\title{
Experimental researches of hydraulic vacuum breakdown devices of siphon outlets of pumping stations
}

\author{
Muzaffar Shomayramov ${ }^{l}$, Behzod Norkulov $^{2 *}$, Javlonbek Rakhmanov ${ }^{3}$, Durdona \\ Tadjiyeva ${ }^{3}$, Javlonbek Suyunov ${ }^{3}$ \\ ${ }^{1}$ Ministry of Water management of the Republic of Uzbekistan. \\ ${ }^{2}$ Tashkent Institute of Irrigation and Agricultural Mechanization Engineers, Waterpower exploitation \\ and pumping stations, 100000, Tashkent, Kara-Niyaziy str. \\ ${ }^{3}$ Samarkand State Architectural and Civil Engineering Institute,140100, Samarkand, Lolazar str.
}

\begin{abstract}
The paper presents the results of experimental researches of siphon outlets, which are used at large machine canals. It has been justified that siphon water outlets of the pumping stations operate in different conditions that siphon spillways at hydroelectric power plants and the mode of their operation have a significant impact on the operation of the pump. In terms proposed by us, the siphon has a constant width, equal to the diameter of the pipeline. The siphon length is reduced by $4.5 \mathrm{~m}$. The height of the ridge is reduced so that the cross- sectional area remains equal to cross sectional area of the pipeline. The descending brunch is made with the same slope $m=1.6$, the cone angle of the diffuser is $a=-6^{0}$. The bottom of the outlet section of the siphon is raised by $2.5 \mathrm{~m}$ against the previous mark, the ceiling is deepened below the minimum water level by $1.0 \mathrm{~m}$., and then smoothly turns up and out for $0,5 \mathrm{~m}$ below the minimum headwater level of the upstream. The proposed version of the siphon when testing on the model was fully included at the maximum flow rate $\mathrm{Q}=18 \mathrm{~m}^{3} / \mathrm{s}$. at a water temperature of $22^{0} \mathrm{C}$.
\end{abstract}

\section{The research goal}

As it is known, the main irrigated areas of Uzbekistan are located above the level of watercourse and therefore they are irrigated by machine lift canals. The water industry of the Republic of Uzbekistan is a complex complex of irrigation and drainage systems, serving about 4.3 million hectares of irrigated land, including more than 180 thousand $\mathrm{km}$ of canal network, 140 thousand $\mathrm{km}$ of collector-drainage network, about 160 thousand structures, of which over 800 large, 1588 pumping stations with an annual capacity of 8.2 billion $\mathrm{kW}, 55$ reservoirs with a total capacity of 19.8 billion $\mathrm{m} 3$ and more than 4,100 wells $[1,2]$. The conversion of electrical energy to hydraulic energy is carried out by pumping stations of various capacities. When ensuring efficient operation of the pumping stations, special designs are used which allow to save energy consumption an increase the

\footnotetext{
* Corresponding author: behzod1983@ mail.ru
} 
productivity of each pump unit.Water outlet siphons belong to such engineering structures $[3,4]$. The implementation of the above- mentioned task is the main purpose of this work.

\section{The research methodology}

The analysis of the existing designs of siphon outflow structures of pumping stations of various capacities changing their designs in order to increase their efficiency and developing new designs of outlet discharge siphon structures of pumping stations.

\section{Results of the research and discussion}

Designs of vacuum breakdown valves(VBV) should provide energy-saving and reliable operating methods at the working ranges of the water level of the upstream [WLU] -[5-8]. The most perfect are hydraulic vacuum breaking devices(HVBD). They have no moving parts, they do not need maintenance. However, for large ranges of WLU, the speed of the reverse flow of water reaches significant values, sufficient for water suction into the pipeline. Such phenomenon is very dangerous.

The reduce the effect of the VBV on the siphon characteristic new designs have been developed[Fig.1].

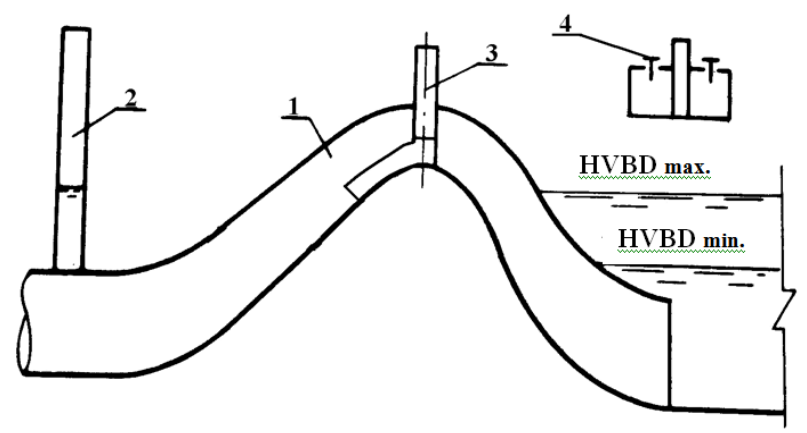

Fig 1. Scheme of HVBD design of KMK and SANIIPI.1. Rising siphon branch; 2- airduct pipe 3.

Speed tube 4. Valve plungers

Siphon water outlets with HVBD are applied at Karshinsky [KMK], Sherabad and other canals $[9,10,11]$.

Air pipe [a,p] is mounted at the end of the pressure pipe below the vacuum zone by the value of the velocity head in cross section, where it is installed. The size of the cross section of air pipe[A.P] is taken 7-8\% of the size of the cross section of the pressure pipe.

When stopping with a delayed opening of the HVBD pulsating loads, the levels of vibration and stresses in the pump elements exceed the corresponding characteristics in the operating modes by 5-10 times which increases the risk of the unit failure.

Reducing the pressure pulsation of the unit was achieved through the use of a fundamentally new hydraulic intensifier, made in the form of a vacuum $\operatorname{tank}(\mathrm{FVT})$, in the installed on the siphon rising branch and applied to the "Abai" pumping station[PS] [Fig.2]. 


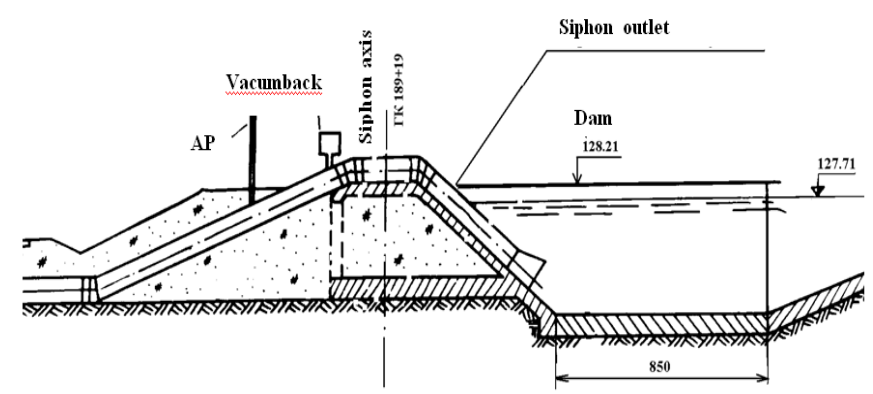

Fig.2. siphon outlet of the pumping station with a vacuum tank.

Tests of OP 10-185, OP-260 pumps, conducted with the participation of the authors showed that the change in pressure pulsations during the shutdown process has the same character at Sherabad pumping station(P.S) and pumping station - 1-KMK.

In the stop mode of the pump unit, Special attention was paid to the beginning of the HVBD operation and the duration of the turbine mode. After turning the pump unit (PU), the reduction of the pump impeller(PI) speed begins, the pressure in the discharge pipe and in the PI chamber of the pipe, the speed of water movement in the forward direction, at the $12^{\text {th }}$ second, the movement of water in the discharge pipe stops, after which the water begins to move in the opposite direction in the pipe, then at 18-20 seconds, the PI of the pumps stops and already at the 32-nd second, the pump picks up speed to 200 r.p.m. To this moment the volume of water in the pipeline turns out almost worked out and the pressure does not exceed 6-8 minutes. In about 1-2 minutes the PI of the pump completely stops(Fig.3). This moment corresponds to the drop up to zero value of all parameters in the NA unit: the pressure at the PI pump pressure, power supply, vacuum in the siphon neck[12-14].
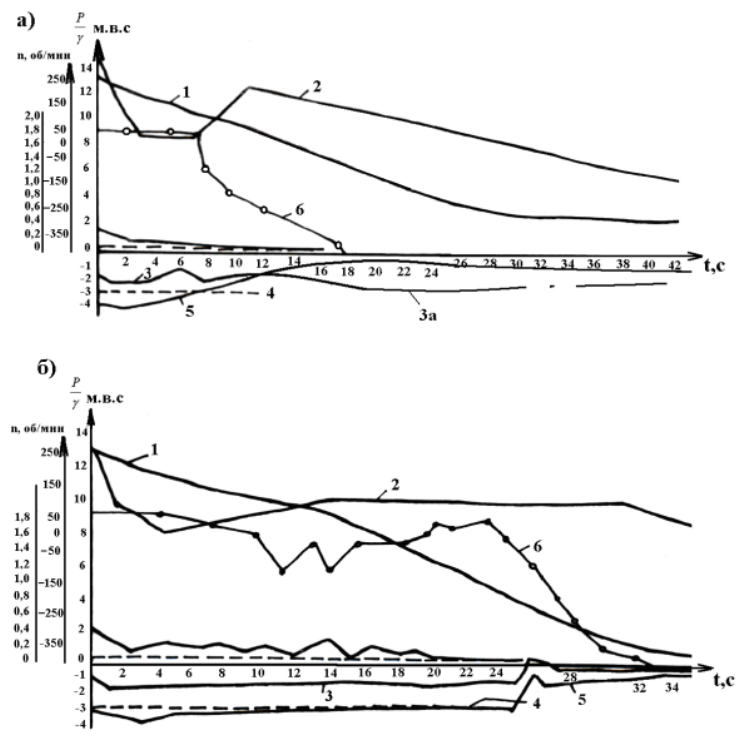

Fig.3. Graphics of changes in the parameters in the throat of the siphon in the process of pump stopping.

1- turns of a pump unit; 2-pressure in the pipeline ; 3 - pressure in the siphon; $3 \mathrm{a}$ also according to the calculation;4-static vacuum; 5- dynamic vacuum;6-water level[WL] in the throat of the siphon 
All these data are interesting because is the help of them we can trace the effect of varies designs of the VBV and HVBD as the siphon outlets of the pumping stations on the flow of the transient processes during the start up, shutdown of the units and charging of the siphon outlet.

At the pumping stations (PS) "Sherabad" and KMK, the duration of the break pump made for OP-10 pumps with a diameters of 185 and $200 \mathrm{~cm}$ ranges from 14 to $19 \mathrm{~s}$.

To the nature and quantitative characteristics of hydraulic shock with discontinuity in addition to the factors of the relative closing time of the regulating device, air content, volumetric content of solid particles also influence such important factors as operating modes of PS, the contour of the pipeline route, the presence of check valves outlets [15].

Laboratory hydraulic researches of the "Sherabad" pumping station (PS) siphon outlet were carried out at the SRIIHP (Fig. 4). According to the project, the station has OPV-10185 pumps with a feed of $18 \mathrm{~m}^{3 / \mathrm{s}}$ each, supplying water to individual pipelines with a diameter of $2.6 \mathrm{~m}$.

The fluctuation level in the pressure pool reaches 1.5. The cross-sectional area of the siphon neck is equal to the cross-sectional area of the pipeline.

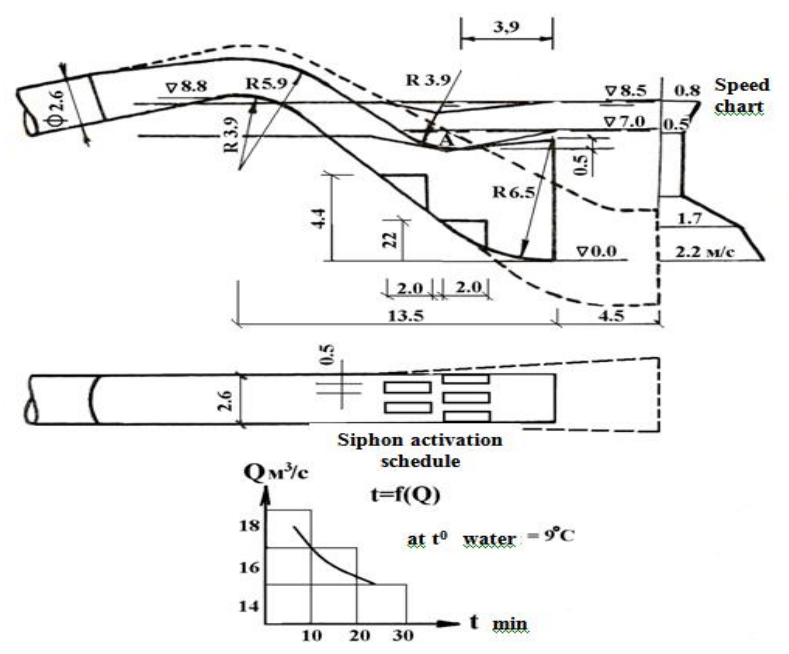

Fig. 4. Siphon outlet: project option, ecommended option.

The siphon of the rectangular section, spending in the plan from the diameter of the pipeline $2.6 \mathrm{~m}$ on the ridge up to 4 meter at the exit. The height of the longitudinal section varies from the diameter of the pipeline on the ridge to 5 meter at the exit. The slope of the downward branch is $m=1.6$, the taper angle is $a=10^{\circ}$. The exit edge of the siphon is recessed below the minimum HWLP at $4.5 \mathrm{~m}$., the bottom is at $9.5 \mathrm{~m}$.

The researches on the model showed that the version of the siphon is turned on very slowly and not until the end.

An air bag remains above the ridge, and approximately at the mark of the HWLP-an intense drum. The poor inclusion of the siphon can be explained mainly by the fact that the upper output edge of the siphon unnecessarily buried under the horizon of water and the stream overflows the ridge before taking the air out should drive it to a rather great depth. In the initial period of inclusion, when the water cushion is low in the descending branch of the siphon, and the pressure line in the pipeline is high, the stream flowing from the ridge receives rather higj speed before entering the water cushion, resulting in intensive aeration of the flow and vigorous removal of air to the outside. In the output of the descending 
branch of the siphon, the water horizon rises, the pressure line in the pipeline decreases, the flow rate before entering the water cushion decreases, the ability to aerate it also decreases and the stream flowing from the ridge is unable to draw air to a great depth-full inclusion of the siphon is delayed for a long time or siphon does not turn on at all.

When choosing a new form of siphon, proceeded from the position that the siphon outlet of the pumping station(PS)being a part of a unified system, work in other conditions than siphon spillways at hydroelectric power stations HEPS and their mode of operation has a significant impact on the operation of the pump[19,20]. If, in the siphon spillways, the intensive inclusion and wide range of operation is decisive which is sometimes achieved by reducing the consumption coefficient, then in the pumping station siphons, an increase of intensity of the siphon inclusion should not lead to an increase of losses in the system[20,21]. It is necessary to look for a solution as much as possible the intensity of inclusion with minimal losses.

The proposed form of the siphon is shown in Fig.4 as a solid line. In the plan the siphon has a constant width equal to the diameter of the pipeline. The length of the siphon is reduced by $4.5 \mathrm{~m}$. The height on the ridge is reduced so that the cross-sectional area remains equal to the cross-sectional area of the pipeline. The descending branch is made with the same slope $m=1.6$, the cone angle of the diffuser is- $a=6^{0}$.

The bottom of the outlet section of the siphon os raised by $2,5 \mathrm{~m}$. against the previous mark, the ceiling is deepened below the minimum water level by $1.0 \mathrm{~m}$. and then smoothly turns up and out by $0,5 \mathrm{~m}$.below the minimum water level of the headwater. The height of the section at the exit is $6,5 \mathrm{~m}$. In the extended outlet part of the siphon, two rows of springboards are installed to prevent the flow separation from the ceiling, for the ore uniform distribution of speeds at the exit. All turns in the siphon are outlined along radii creating minimal losses.

The proposed version of the siphon when tested on the model was fully included at the maximum flow rate $\mathrm{Q}=18 \mathrm{~m}^{3} / \mathrm{s}$. at a water temperature $22^{\circ} \mathrm{c}$. at lower cost, the air bag remained on the ridge. At lower water temperature $\left(9^{0} \mathrm{c}\right)$, the siphon was turned on at all operating costs.

When choosing the recommended form of narrowing of the siphon neck and the form of

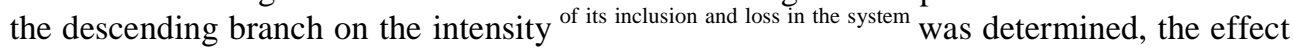
of water temperature on the siphon operation with open and closed valves on losses in the system[18-19].

When you turn off the pump, water in the pipeline rushes in the opposite direction, causing the formation of a vacuum of greater magnitude than with direct current. The equality in the magnitude of the vacuum in the forward and reverse current increases due to a springboard. A local overpressure is formed on front of the springboard with a direct current of water, and a higher vacuum as a result of the extraction of the stream.

Water in an inclined part of the atmosphere pipe \, when a reserve flow of water in the pipeline begins, rises above the ridge of the atmosphere pipe, and begins to be sucked off the siphon. The siphon pumping water from the cavity of the atmosphere pipe begins to suck a large amount of air through the open end of the atmosphere pipe and a small amount of water entering through the connecting pipe from the upper pool; as a result $\backslash$, the vacuum in the siphon is broken and the reverse flow of water in the atmospheric tube and as low as possible, so that a strong jet of water, coming out of this tube during the shutdown period did not abstract the passage of air from the open end of the atmosphere tube into the open end of the atmosphere tube into the siphon cavity at the cutting edge.

The described HVBD was tested on the model of the Sherabad Piping station(P.S) $(\mathrm{M}=1: 30 \mathrm{NV})$. The hydraulic shutter on the model works reliably in the given limits of fluctuation of the HWLP. Breakdown of the vacuum at reverse current starts at 25 seconds 
after the beginning of the reverse flow of water (time is recalculated for natural conditions) and continues until the pipeline is completely empty.

\section{Conclusions and recommendations}

1. As a result of the carried out researches the necessity of improving the operation of the P.S siphon outlets with vacuum breakdown devices based on a scientific analysis of the current state of their operation has been justified. HVBD with new elements allow to expand the range of their application on the siphon outlets of pump units(PU).

2. New designs of HVBD are tested on the model of the Sherabad Pumping Station. Their implementation at large pumping units (PU)of the Republic and the obtained positive effect proves the promise of scientific and constructive development.

The authors of this scientific work express their sincere appreciation for the opportunity to conduct a survey in the library of the Department "Use of Water Energy and Pumping Stations" of the Tashkent Institute of Engineers of Irrigation and Agricultural Mechanization, Head of the Department, full member of the International Academy of Ecology and Human Safety, Doctor of Technical Sciences, Professor Dilshod Rayimovich Bazarov. And also, for the opportunity to get acquainted with the materials of field studies of large pumping stations of the Republic of Uzbekistan for the opportunity provided to employees of the Pumping Station Administration of the Ministry of Water Resources. The authors consider it their duty to particularly note the great assistance of the administration of the Tashkent Institute of Engineers of Irrigation and Agricultural Mechanization, represented by the Rector - Doctor of Economic Sciences, Professor Uktam Pardaevich Umurzakov, who presented her scientific library and created a cozy atmosphere for writing real scientific work, and provided financial support up to the publication.

\section{References}

1. Bazarov D.R., Arifjanov va boshq. Uzandagi jarayonlar, T. TIQXMMI, 2018, 641p.

2. Bazarov D.R. and others. NTO on $\mathrm{x} / \mathrm{d}$ on the topic №17 / 2017 "Development of recommendations for the prevention of channel deformations in the downstream pools of reservoirs" MAWR, Tashkent 2017, $80 \mathrm{p}$.

3. Zuykov A.L. Hydraulics Volume 1 M., due to the TSF NRU MSSUB 2016, p.456.

4. Bazarov D.R., Karimov R.M., Hidirov S.Q., Matyakubov B.SH. GIDRAVLIKA I ASOSIY KURS, TIQXMMI, $641 \mathrm{p}$.

5. Shtilman V. B. Assessment of the reliability of mechanical equipment of NPP hydrotechnical structures // Scientific and technical problems of predicting the reliability and durability of structures and methods for solving them. Works of the 4th International Conference. S.-Nb.: SNbGTU. 2001. p. 370-372.

6. Talipov, S., Irisboev, Z. - Uzbekistan, Republic of Yidirik, Va, Muram, Hydraulic Engineering, Inspecting Havis Ligging Davlat Nazorati, Increasing Efficiency, Reliability and Safety of Hydraulic Structures: Materials of the Republican Scientific Practical. conf. December 13-14, 2012. - Tashkent, 2012. - p. 129-131

7. Solnyshkov V.A. Optimization of the reliability of structures and mechanical equipment of the water throughput tracts of hydraulic structures. AutoRef Dr. tech. sciences. Leningrad 1972.40s.

8. Petrenko S.Ye. Parameters of reliability of operation of pumping stations and measures to improve them. Engineering Bulletin of the Don. 2010. №4. Pp. 110-114.

9. Ochilov R.O., Uralov B.R., Glovatsky O.Ya. New methods for cleaning the supply channel of the Karshi main canal Hydrotechnical engineering inspecting the 
samarodorligini, and the nongligigi va havfisligini oshirish maususidagi Republic Ilmi amalia Toshkent 2012 conference. 396-399 s.

10. Muhammadiev MM, Urishev B.U. and others. Energy-efficient technologies in the operation of pumping stations. Monograph. - T .: Tashkent State Technical University, 2012, $102 \mathrm{p}$.

11. Mamajonov M. Analysis of the operating conditions of pumping stations for agricultural purposes. // Bulletin of agrarian science of Uzbekistan. Tashkent GAU.Tashkent: 2004, No. 1, pp.77-80

12. Shomayramov MA, Glovatsky O. Ya. Development of devices with hydraulic automation means for unsteady operation modes of pumping stations // Scientific and practical journal "Ways to improve the efficiency of irrigated agriculture" Novocherkassk, 4 (72), 2018. - 175-180

13. Shomayram MA Constructions of siphon outlets with vacuum breakdown devices // Agriculture of Uzbekistan. Tashkent, 2008. -3. -with. 25-26

14. Glovatsky O.Ya., Rustamov Sh.R., Sharipov Sh.M. Security management methods for interconnecting pumping station facilities // Collection of reports at the II International Scientific and Practical Conference "Scientific support as a factor in sustainable development of water management" - Kazakhstan, 2016. -p.143-146.

15. Karelin V.Ya. Cavitational phenomena in centrifugal and axial pumps. -M.: Mashinostroenie.1975.-336s.

16. Keberle S.I., Glovatsky O.Ya. Work avankamer pumping stations and recommendations for improving their structures. / / Hydraulics and land reclamation. 1977, No. 7, p. 3641

17. Kamalov TS, Kholikov SS, Tozhiev U.A. The question of the risk and safety of pumping stations and cascades of a water-driven station. // Problems of computer science and energy. 2006, No. 6. p.36-42.

18. Baryshnikov N.B. Hydraulic resistance of river channels St. Petersburg, Izd.RGTMU, 2003.147s

19. Petrenko S.Ye. Parameters of reliability of operation of pumping stations and measures to improve them // Engineering Bulletin of the Don. 2010. 4. Pp. 110-114.

20. Bazarov D.R., Karimov R.M., Hidirov S.Q., Matyakubov B.SH. GIDRAVLIKA I ASOSIY KURS, TIQXMMI, 526 p.

21.Zuykov A.L. Hydraulics Volume 2 M., NRU MGSU 2016, p.423 